\title{
A VIOLÊNCIA (CRIMINOSA) DA ATUAÇÃO PENAL ESTATAL E SUA INSUSTENTABILIDADE SOCIAL: RETRATOS DE UM ESTADO DE POLIICIA BRASILEIRO
}

THE (CRIMINAL) VIOLENCE OF STATE CRIMINAL ACTION AND ITS SOCIAL UNSUSTAINABILITY: PORTRAITS OF A STATE OF BRAZILIAN POLICE

Felipe da Veiga Dias

Augusto Jobim do Amaral

\section{RESUMO}

O presente estudo tem como tema a criminologia crítica e a sustentabilidade social, com ênfase na violência estatal, em especial da força policial. Tem-se como problema de pesquisa como alcançar a sustentabilidade social com o atual perfil de intervenção penal-policial sobre a população brasileira? Conclui-se que diante do quadro de expansão do Estado de Polícia, torna-se inviável qualquer projeto de sustentabilidade social, já que se ignoram os danos sociais massivos e desigualdades produzidos pelo sistema penal. Por fim, a metodologia empregada compreende uma abordagem fenomenológico-hermenêutica, um método de procedimento monográfico e técnica de pesquisa por documentação indireta.

Palavras-chave: Criminologia crítica. Sustentabilidade social. Estado de Polícia.

\section{ABSTRACT}

The present study focuses on critical criminology and social sustainability, with emphasis on state violence, especially the police force. Do you have as a research problem how to achieve social sustainability with the current criminal-police intervention profile on the Brazilian population? It is concluded that in view of the expansion of the State of Police, any social sustainability 
project is unfeasible, since the massive social damages and inequalities produced by the penal system are ignored. Finally, the methodology used includes a phenomenological-hermeneutic approach, a method of monographic procedure and research technique by indirect documentation.

Keywords: Critical criminology, Social sustainability, Police State

\section{INTRODUÇÃO}

0 presente estudo tem como tema central a violência a partir da apreciação criminológico-crítica e da sustentabilidade social. Esses dois pontos de convergência amparam-se em objetivos comuns, no sentido da oposição à opressão de sujeitos vulneráveis, bem como na melhoria das condições de vida dos seres humanos.

Com a finalidade de especificar a temática realiza-se a sua delimitação no espectro da violência realizada pelo Estado, com destaque para as forças policiais que aplicam os ditames do sistema penal sobre a população. Justifica-se tal especificação em razão dos resultados danosos produzidos por essa intervenção, tanto no aspecto de desigualdades sociais quanto de produção direta de letalidade.

Dito isso, apresenta-se como problema de pesquisa a questão seguinte: existe como alcançar a sustentabilidade social com o atual perfil de intervenção penal-policial sobre a população brasileira? Objetivando responder a tal reflexão traça-se uma linha de abordagem metodológica fenomenológico-hermenêutica, valorando os elementos utilizados por sua inserção contextual e não os caracterizando por uma quididade real. Juntamente a essa perspectiva estão os métodos de procedimento monográfico e a técnica de pesquisa por documentação indireta, com ênfase em bases bibliográficas e dados de pesquisas empíricas.

Com base nisso estruturam-se três camadas a fim de alcançar as respostas ao problema proposto, sendo a primeira delas a definição das bases da sustentabilidade social, já que estas contrastam os modelos sociais hodiernos e pretendidos, junto à compreensão da violência. Na segunda parte se congregam as bases iniciais aos pressupostos da criminologia crítica, a qual soma ainda sua autorreflexão epistemológica 
para com isso contribuir de forma mais eficaz na exposição das desigualdades e danos sociais produzidos por mercados e Estados. Por fim, adentra-se na violência policial enquanto instrumento do Estado de Polícia, verificando seus processos contemporâneos de legitimação (ou até legalização) no uso da violência (dita) legítima no país e sua compatibilidade com os parâmetros criminológicos e de sustentabilidade em busca de uma sociedade mais equânime, menos violenta e desigual.

\section{A SUSTENTABILIDADE SOCIAL E A VIOLÊNCIA COMO PADRÃO DE INCOMPATIBILIDADE}

0 atual contexto nacional apresenta um cenário problemático acerca de diversos aspectos da vida cotidiana, desde questões básicas de saneamento e saúde até a segurança pública. Com base nisso pretende-se observar esse quadro a partir do que seria uma sociedade socialmente sustentável, dando ênfase às atuações estatais no plano criminal. Para tanto, faz-se necessário traçar as bases dessa concepção, bem como debater acerca da própria compreensão do que seria a violência, haja vista ser o Poder público o detentor do seu monopólio (em tese) legítimo.

Inicialmente, as construções sobre a sustentabilidade em sentido amplo remontam períodos antigos, segundo autores seu uso se dá desde o medievo (BOFF, 2015, p. 32 - 33), porém, interessa por ora apontar que suas bases são traçadas com base no ponto de vista europeu. Ainda assim não se desconhece que por se tratar de uma concepção ampla e em franco desenvolvimento, existem diversas contribuições latinoamericanas (pensamento decolonial) (BRAGATO, 2014, p. 211 -212), as quais ofertam inserções diferenciadas (conforme se observa no exemplo da Pachamama) (BOFF, 2015, p. 62).

Observa-se nas primeiras formas de utilizar a sustentabilidade a conexão com o tema da escassez, contudo, no presente momento essa linha de raciocínio é insuficiente, pois segrega a sustentabilidade a ser uma mera ferramenta inoperante em um sistema globalizado de exploração da natureza (BOSSELMANN, 2015, p. 41 - 42). Em síntese, a sustentabilidade defendida pela maior parte dos autores não se reduz a 
um mero operativo ou paliativo, mas se trata de uma mudança de postura do ser humano em seu modo de viver no planeta e com os demais seres vivos e não vivos.

Posto isso, percebe-se que ao contrário do que usualmente se adota a noção de sustentabilidade não se encontra restrita à apreciação de demandas ambientais, ou seja, se ela serve como novo paradigma de vida na Terra, significa que suas dimensões são mais amplas do que a veiculação recorrente faz crer. Neste sentido, apregoa-se no mínimo três dimensões diferentes para sustentabilidade, com base no modelo de Elkington: ambiental, econômica e social (ELKINGTON, 1998).

Essa alusão não exclui outras vertentes, apenas denota os elementos essenciais à presente proposta, já que a indagação acerca da atuação das instituições estatais contra sua própria população diz respeito muito mais ao plano social do que as preocupações socioambientais. Destarte, independente do conceito utilizado, qualquer adoção da sustentabilidade social remete umbilicalmente à busca por melhores condições de vida, equidade e justiça social (MCKENZIE, 2004, p. 6), sendo que a problematização surge especialmente da inviabilidade dessas pretensões quando o próprio Estado atua de forma violenta e discriminatória.

Logo, percebe-se que a sustentabilidade é algo que deve afetar o Estado e suas ações, ao menos essa é a compreensão de Canotilho, que afirma: "a sustentabilidade configura-se como uma dimensão autocompreensiva de uma constituição que leve a sério a salvaguarda da comunidade política em que se insere" (CANOTILHO, 2010, p. 8). Por óbvio que a leitura do autor remete à previsão da sustentabilidade no texto constitucional português (seja diretamente, seja indiretamente), mas isso em nada impede a compatibilização nacional, visto que além do artigo 225 da Constituição (BRASIL, 1988), a noção sustentável do meio ambiente e porque não dizer da sociedade pode ser abstraída dos diversos dispositivos que se debruçam sobre o tema durante a sua exposição.

Ainda de acordo com o autor português a sustentabilidade enquanto fundamento social contemporâneo implica ao menos três dimensões básicas de operacionalização jurídico-política, as quais seriam: (a) a sustentabilidade entre Estados, no sentido da obrigatoriedade de maior "equidade entre países pobres e ricos"; (b) a segunda via se 
trata da sustentabilidade entre gerações, abrangendo o equilíbrio entre indivíduos de diferentes faixas etárias; (c) e, por fim, a sustentabilidade intergeracional "impositiva da equidade entre pessoas vivas no presente e pessoas que nascerão no futuro" (CANOTILHO, 2010, p. 8 - 9).

Assim, pode-se dizer que ao tomar a sustentabilidade social como parâmetro, surge a imposição de um repensar sobre os rumos elegidos para a humanidade, ou seja, é forçoso rearticular o Estado e as instituições para darem a resposta adequada aos novos paradigmas. Essa obrigatoriedade toma forma a partir da insuficiência em adimplir com objetivos tão complexos no atual contexto (MORIN, 2015, p. 25 - 26).

Igualmente, tais instituições e o próprio Estado ainda estão presos nos pressupostos da modernidade e que não podem ser mantidos. Portanto, a visão individualista-antropocêntrica de mundo alicerçada em um processo de mal-estar (psíquico e moral), aliado à perspectiva consumista que agrava as desigualdades sociais dos mais vulneráveis e ignora os corpos pelo caminho não pode ser aceita como uma mera crise desse período, sendo inafastável a sua renovação (MORIN, 2015, p. 26).

O desafio de repensar o Estado já é largamente debatido, sendo a inclusão da sustentabilidade um fator a impulsionar novas estratégias e políticas capazes de modificar a sociedade, conforme aborda Morin com suas proposições de políticas da humanidade e da civilização (MORIN, 2015, p. 56), mas sempre em prol da formação de uma sociedade mais justa e equilibrada. Com fulcro em tais alterações, uma das bases do Estado durante a modernidade sempre foi a dominação como característica, tanto no plano externo quanto interno, já que o controle penal tem esse objetivo. Todavia, segundo a leitura de Boff esta nuance não seria passível de manutenção, tendo a ideia do cuidado como seu substituto (BOFF, 2016, p 20).

A título exemplificativo a alusão anterior iria impor ao Estado a obrigação de projetar outra forma de sanção penal, pois os atuais modelos de privação de liberdade funcionam como máquinas de dominação da alma (na visão de Foucault) (FOUCAULT, 2003) e não como ferramentas de cuidado para uma autorreflexão contraposta a atos violentos. Ademais, o reconhecimento da singularidade e importância de cada ser vivo com 
base na ideia de cuidado carece da preservação de todo e qualquer ser vivo, sem negar a existência do outro.

Portanto, a atual postura estatal penal albergada na dominação e apartada da noção de cuidado afronta claramente a sustentabilidade social (BOFF, 2015, p. 93). Até mesmo porque se poderia mencionar no mínimo a violação ética na manutenção dessa forma de abordagem, o que igualmente entraria em choque, já que toda a ideia de sustentabilidade é em essência uma perspectiva ética (BOSSELMANN, 2015, p. 25).

Toda essa argumentação parte do pressuposto do equívoco nas ações estatais, as quais se amparam no uso da violência legítima para justificar tais atos. No entanto, a delimitação do que se entende por violência se justifica, a fim de com isso circunscrever os limites dessa atuação e quais condutas não seriam adequadas ao plano de uma sociedade sustentável.

A sustentabilidade social pressupõe um projeto de sociedade em cooperação, ou seja, capaz de traçar objetivos comuns para a melhoria nas condições de vida, e isso se afasta das ações violentas, já que estas resultam em processos de afastamento e determinação de objetivos diferentes (ARENDT, 1998, p. 193). Portanto, a violência deve ser percebida em sua instrumentalidade, de maneira que seu uso tenta amplificar a potência (entendida enquanto fator individual) com a finalidade de realizar a submissão (ARENDT, 2006, p. 60 - 64).

Nas definições contemporâneas da violência esta aparece de forma contumaz ligada à ideia de poder, neste sentido basta verificar a conceituação da Organização Mundial da Saúde (OMS), a qual refere-se à violência como todo uso de força física ou poder em ameaça ou na prática contra pessoas ou grupos, que possam ocasionar sofrimento, privações, danos psicológicos, prejuízos de desenvolvimento ou até mesmo a morte (WORLD HEALTH ORGANIZATION, 1996). Isso indica que por mais que se saiba de classificações distintivas entre poder e violência, o seu uso conjunto de justifica fenomenologicamente (ARENDT, 2006, p. 72), pois basta para tanto observar que a noção de poder punitivo estatal encontrase diretamente conectada ao uso da violência.

Porém, a definição de violência supramencionada encontra-se presa a noção de intencionalidade, de maneira a excluir condutas ditas "acidentais" (DAHLBERG; KRUG, 2006, p. 1165), algo que gera efeitos 
sob o viés dos objetos criminológicos, mas que se retomará na segunda parte do estudo. Ademais, a proposta da Organização Mundial da Saúde traz uma tipologia valiosa sobre três grandes grupos de violência, sendo duas delas focadas em comportamentos autoinflingidos e de cunho interpessoal, mas contando com uma última parcela focada em atos violentos de natureza coletiva, dentre os quais encontram-se os fatos que ocorrem em "âmbitos macrossociais, políticos e econômicos e caracterizam a dominação de grupos e do Estado", bem como se aludem "crimes cometidos por grupos organizados, os atos terroristas, os crimes de multidões, as guerras e os processos de aniquilamento de determinados povos e nações" (COELHO; SILVA, LINDNER, 2014, p. 13).

Apenas em adendo cabe mencionar a inclusão posterior da violência estrutural, a qual se refere aos processos "sociais, políticos e econômicos que reproduzem a fome, a miséria e as desigualdades sociais, de gênero e etnia" (COELHO; SILVA, LINDNER, 2014, p. 14). Contudo, ao inserir esse componente infere-se que a categoria geral da violência fica passível de contestação, visto que a violência estrutural é em geral naturalizada culturalmente, não sendo uma atuação intencional no sentido de produção de danos, mas que ainda assim é considerada como forma de uso de poder e opressão.

Emboraalém dos grandes grupamentos citados existam classificações a respeito da natureza da violência (como sexual, física, psicológica, etc.) (DAHLBERG; KRUG, 2006, p. 1166), o que se torna mais relevante ao pensar as ideias de uma sociedade sustentável diz respeito a primeira parte, em especial aqui as ações violentas de ordem coletiva e estrutural capitaneadas pelo Estado no uso de sua autoridade no manejo do poder punitivo e de seu monopólio sobre a violência dita como legítima ${ }^{1}$.

Essa visão combinada entre os grupamentos (coletivo e estrutural), juntamente à conceituação geral, oferece um catálogo peculiar na interpretação do que seria uma violência e de como o Estado também pode ser um agente a gerar fenômenos lesivos. Ao mesmo tempo em que ao intercalar isso com as noções da sustentabilidade, se compreende que a redução máxima dessas condutas é imprescindível à formação de uma nova sociedade, pois as bases da sustentabilidade estão na conjugação 
de objetivos e na ampliação da qualidade de vida, algo completamente oposto à violência estatal que segmenta e incrementa desigualdades.

Diante disso, carece-se do entendimento sobre a atuação penal nesse contexto, a fim de com isso verificar se as atuais posturas do Estado podem ser encaixadas nesses traços da violência, os efeitos gerados a partir dessas condutas, bem como se os objetos definidos pela criminologia são capazes de darem respostas às intervenções penais hodiernas.

\section{INTERVENÇÃO DESIGUAL DO SISTEMA PENAL: NOVOS PARADIGMAS CRIMINOLÓGICOS PARA O ESTUDO DA VIOLÊNCIA ESTATAL}

Quando se pensa no sistema penal deve-se ter mente que este se trata de uma forma complexa de manifestação de poder. Esse mesmo poder de uso exclusivo da violência se encontra legitimado pelos pressupostos racionais que devem sustenta-lo, sendo que tais bases são mantidas por um discurso de fundamentação, de modo que a legitimidade da intervenção estatal depende dessa manutenção de racionalidade do mesmo discurso (ZAFFARONI, 1991, p. 16).

Nesse sentido, o sistema penal apresenta seus traços de incoerência na impossibilidade de efetivar seus próprios objetivos, ou seja, seu cumprimento é impossibilitado pela realidade (punir toda a população na maior parte do tempo não seria viável) e resta a ele apenas entrar em contradição. Demonstração dessa afirmativa é a proclamação da igualdade interventiva (BARATTA, 2002, p. 42) que acaba por concretizarse somente como uma atuação seletiva e discriminatória, amparada na ideia de legalidade, mas frise-se: legalidade e legitimidade não são o mesmo elemento (ZAFFARONI, 1991, p. 29).

Portanto, evidencia-se que a deslegitimidade da atuação estatal penal, amparada na sua incoerência legal, deixa clara a sua diferença entre as funções anunciadas pelo sistema e aquelas que efetivamente ele pretende atender. Essa distinção entre funções declaradas e não declaradas demonstra o que Andrade trata como eficácia invertida, 
ao dizer que o sistema penal não se preocupa verdadeiramente em combater a criminalidade ou proteger interesses juridicamente relevantes para população, mas sim atenta em construir ações seletivas e estigmatizantes, "e neste processo reproduzir, material e ideologicamente, as desigualdades e assimetrias sociais (de classe, de gênero, de raça)" (ANDRADE, 2012, p. 136).

As indicações acima fragilizam os alicerces estatais no uso de seu poder/violência em sociedade, pois ao demonstrar que a lei enquanto instrumento jurídico não se presta à construção de um modelo social sustentável e mais equilibrado aos seres humanos, perde-se sua principal função. Em síntese, torna-se viável dizer que a lei é utilizada como instrumento de poder, já que serve para representar interesses dos grupos dominantes, bem como para conservar o próprio poder, ao invés de consolidar objetivos comuns (ao menos em matéria penal) (PAVARINI, 2002, p. 138).

No entanto, a abordagem dos problemas causados pelos órgãos de controle social somente se tornou possível a partir da modificação criminológica de paradigma, ou seja, com a adoção da perspectiva da reação social e a teoria da rotulação (labelling approach) (LARRAURI, 1992, p. 28). Isso significa que ao atentar aos instrumentos estatais que definem e perseguem o desvio, juntamente às reações sociais necessárias à coerção de indivíduos, ganha-se em fundamentos de deslegitimação da atuação penal.

Ademais, essa nova compreensão se dá com a modificação dos questionamentos que movimentam os estudos criminológicos, no sentido de indagar quem define os sujeitos desviantes, os efeitos dessa delimitação, ou ainda quais sujeitos definem tais situações como "crimes". Agregam-se nuances a respeito da atuação direta dos órgãos de controle, como a atribuição do rótulo de desviante a sujeitos selecionados, e ao mesmo tempo também os debates anteriores a respeito da confecção de leis que já têm seus alvos pré-estabelecidos (BARATTA, 2002, p. 88 - 89).

Salutar mencionar que essas construções foram aprofundadas em nível de criminologia crítica, pois as noções do desvio primário, por exemplo, são atribuídas à utilização dos grupos de poder nas definições da criminalização como forma de seleção e da implementação da lógica 
capitalista (BUDÓ, 2013, p. 41). Significa dizer que as construções criminológicas são aprimoradas a partir da lógica de não superação/ abandono das concepções anteriores, de maneira que as teorias da reação social serviram de base às atuais abordagens criminológicas críticas.

Dito isso, ainda se faz necessário esclarecer o funcionamento da seletividade penal, visto que a simples imputação seria insuficiente para descreditar a atuação do poder punitivo estatal. Partindo-se do ponto de vista de que as ações consideradas como criminosas são praticadas por diversas pessoas e ao mesmo tempo esses agentes são em outras condições vítimas de ações, toma-se como base a noção de que:

Ora, se a conduta criminal é majoritária e ubíqua e a clientela do sistema penal é composta, regularmente e em todos os lugares do mundo, por homens adultos jovens, pertencentes aos mais baixos estratos sociais e em grande medida não brancos, isto significa que a impunidade e a criminalização (e também a vitimação) são orientadas pela seleção desigual de pessoas, de acordo com uma fortíssima esteriotipia presente no senso comum e nos operadores do controle penal, e não pela incriminação igualitária de condutas, como programa o discurso jurídico-penal (ANDRADE, 2012, p. 138).

Apenas para mensuração do impacto dessa seletividade estigmatizante Stiglitz aborda a margem de danos causados pelo registro criminal de um indivíduo (mencionando os estudos de Devah Pager) combinados com as discriminações implícitas. Com base em uma pesquisa de campo em que jovens com cerca de vinte e três anos, com e sem registro criminal, apresentaram currículos idênticos, contatou-se que além da óbvia chamada de retorno maior daqueles sujeitos sem registro, o aspecto racial tinha um peso considerável, pois proporcionalmente era mais vantajoso ser um jovem branco com registro do que negro sem registro criminal, ao menos quando se mensura oportunidades de emprego (STIGLITZ, 2016, p. 136 - 137).

0 resultado supramencionado demonstra a extensão dos efeitos do sistema penal na exclusão social seletiva, de maneira que o processo de criminalização não se esgota na dimensão política ou na simples acepção de dominação dos grupos mais fortes, ou seja, na simples adoção normativa de criminalização primária. Isso significa que se passa por um 
processo de valorações políticas discriminatórias para ao final atingir determinados sujeitos, compondo essa óptica os órgãos de controle, o que formata a seleção na criminalização secundária (PAVARINI, 2002, p. 147) e terciária.

Diante desse quadro de intervenção estatal penal desigual/seletivo, incompatível com a legislação e, por conseguinte ilegítimo, inviabiliza-se o aceite (mesmo em doses mínimas) na adoção da violência enquanto instrumento do poder punitivo do Estado. Ao menos esse seria o raciocínio mais evidente, haja vista que ao pensar em uma sociedade socialmente sustentável em um Estado de Direito as ações violentas deveriam ser reduzidas ao máximo, bem como careceriam de legitimidade para que não gerassem efeitos negativos sobre a maximização da qualidade de vida e da melhoria de condições humanas e não humanas no Terra.

Posto isso, justifica-se neste estudo a adoção da criminologia crítica para observar a atual intervenção estatal, pois tendo em vista que em suas linhas teóricas encontram-se os fundamentos trilhados pelas perspectivas tanto do labelling approach quanto da sociologia do conflito, esta última encarregada de desconstruir o suposto consenso social acerca dos interesses protegidos pelo sistema penal (CARVALHO, 2013 , p. 283 - 284). Além disso, o aprimoramento inicial dado pelos estudos marxistas que evidenciam o poder econômico (bem como a submissão do Direito ao seu poder) e as classes sociais como aspectos a serem considerados na leitura da atuação penal foram expandidos, sendo que hoje a criminologia crítica denota todo e qualquer posicionamento teórico que ao se postar negativamente "a antigas formas de saber e a pressupostas hierarquias do saber, também desafia os arranjos sociais e políticos naturalizados que dão origem a desigualdades de riqueza, conhecimento e poder, com seus acompanhantes sistema de justiça criminal exploradores" (CARLEN, 2017, p. 24).

Valioso citar que a inconformidade com a naturalização de processos de desigualdades é além de um denominador comum entre abordagens de sustentabilidade e criminologia crítica, também um indicativo dos processos de autocrítica do papel desta última na legitimação social de discriminações seletivas. Menciona-se tal reflexão ao observar as questões ligadas ao caráter "científico" (de raiz criminológica) que 
fundamentou durante anos a seletividade e eliminação de negros e índios no Brasil, com base em uma suposta inferioridade racial (CARVALHO; DUARTE, 2017, p. 26 - 27).

Essa autorreflexão se estende para além de objeções históricas e atinge a forma como o conhecimento criminológico foi e ainda é construído, bem como a ausência do lugar de fala de todos os sujeitos invisibilizados pela própria criminologia crítica, ou seja, mesmo que atualmente se clarifique tais falhas, não há como negar que o silêncio acadêmico contribuiu para o reforço das mesmas desigualdades, opressões e dominações (racistas) que se combatem nas linhas criminológicas críticas hodiernas (FREITAS, 2016, p. 491 - 492).

Porém, é contributivo aduzir que a consolidação constante do autoquestionamento por parte da criminologia crítica traz adições consideráveis, sendo que algumas delas merecem destaque posterior, tendo em vista a sua capacidade modificativa nos paradigmas da área.

Assim os estudos criminológicos revelam que os efeitos deletérios causados pela intervenção estatal penal vão além da falta de legitimidade ou de credibilidade, já que os prejuízos humanos ligados à violência institucional não ficam restritos à órbita jurídica, algo que precisa ser denunciado, sob pena de inviabilizar qualquer expectativa de uma sociedade socialmente sustentável. Com base nisso se pode inferir que o padrão estatal penal contemporâneo ressalta a passagem moderna de uma sociedade inclusiva para uma sociedade de exclusão, desintegrando desde comunidades até relações de trabalho (YOUNG, 2002, p. 23).

A exclusão social alimentada pelo sistema penal deixa um rastro de desigualdades bastante diversificado, indo desde questões raciais a gênero, aumentando as tensões e incongruências entre camadas inteiras da sociedade. Esse abismo criado dificulta qualquer ideal de coesão social, e pode ser visto nos últimos anos deste modo:

À medida que os ricos ficam mais ricos, têm mais a perder com as tentativas de restringir as atividades de rente-seeking e de redistribuir os rendimentos de modo a criar uma economia mais justa, e têm mais recursos com que resistir a tais tentativas. Pode parecer estranho que à medida que a desigualdade tem aumentado, temos feito cada vez menos para atenuar o seu impacto, mas não podíamos esperar outra coisa. É decerto o que vemos pelo 
mundo: as sociedades mais igualitárias trabalham mais para preservar a coesão social; nas sociedades mais desiguais, as políticas governamentais e outras instituições tendem a alimentar a persistência da desigualdade. Este padrão tem sido bem documentado (STIGLITZ, 2016, p. 143).

O caso nacional encaixa-se no modelo de alta desigualdade, sendo o sistema penal um componente significativo na manutenção e crescimento desse fenômeno no país. Afirma-se isso tendo consciência de que a violência, em tese legítima, acaba por se tornar um instrumento de classe, dominação e opressão, ao invés de funcionar como último recurso estatal diante de suas falhas na prevenção e estruturação de vidas em seu território.

Basta verificar que as tentativas de apoio aos mais pobres são usualmente vistas como desperdício de dinheiro ou mesmo como escusas a essas pessoas inaptas para o trabalho, de modo a fundamentar a desarticulação de políticas e ações que visem reduzir desigualdades (WACQUANT, 2007, p. 36). Ao mesmo tempo, ainda que em face de uma crise econômica recente o quadro do capitalismo seja a parcimônia, as opções políticas traçadas - entre o retorno a uma expansão keynesiana diluída ou o endurecimento neoliberal - pouco importam, pois o resultado será inevitavelmente o benefício de poucos bilionários que constituem "hoje uma plutocracia cada vez mais poderosa, tanto dentro dos países como no cenário mundial [...]. Em toda a parte, os ricos estão cada vez mais ricos" (HARVEY, 2016, p. 10 - 11).

Contudo, o padrão estabelecido do sistema penal não é apenas seletivo e discriminatório contra as pessoas na base da pirâmide social, mas é igualmente superprotetor daqueles que estão acima. Destarte, os mecanismos de violência estatal não são movidos contra determinados indivíduos, mas antes disso existem mecanismos de imunização (PAVARINI, 2002, p. 148), os quais nem ao menos permitem que suas condutas sejam criminalizadas (e caso sejam ainda contam com outros subterfúgios).

Há com isso a constatação do problema, porém segundo os objetos usuais da Criminologia os atos guarnecidos de determinadas classes sociais não se configuram em condutas criminosas e tampouco encaixam- 
se nas ações criminalizantes dos órgãos de controle social. Novamente a autorreflexão criminológica acaba imposta sobre seus próprios objetos de pesquisa, a fim de possibilitar a entrada nesta seara, pois enquanto não faz isso permanece contribuindo para a violência e opressão contra pessoas que estão à margem da sua observação (ZAFFARONI, 2012).

Portanto, para contribuir mais significativamente com as noções da sustentabilidade social, torna-se imperioso inserir a rearticulação epistemológica. Essa ruptura amplia significativamente o campo criminológico, de modo a permitir abordar desvios cometidos por Mercados e Estados e que geram os denominados danos sociais massivos, compreendendo violações ambientais, omissões em prestações de serviços públicos ou ainda atos violentos de grandes proporções (BUDÓ, 2016, p. 129).

Há uma dupla importância na quebra epistemológica, já que tanto esta serve como questionamento do papel científico desempenhado pelos estudos criminológicos na legitimação de processos de opressão e violência (SARMIENTO et al., 2014, p. 42), quanto para desvelar searas inteiras, em campos como a economia, política, cultura e que por não configurarem a entidade nomeada como crime acabavam deixadas de lado em comparação a outros temas (CARLEN, 2017, p. 22). Logo, os atos do Estado que se encontram dentro da "legalidade", embora claramente ilegítimos, passam a ser um plano possível de exploração, pois os danos massivos gerados por suas condutas violentas já foram evidenciados.

Esse novo olhar ofertado pela criminologia crítica demanda tempo e esforço por parte de seus defensores, já que qualquer ruptura enfrenta suas resistências. Todavia, isso se torna necessário para a devida confirmação de sua valia ao evidenciar os crimes corporativos e estatais para além das definições jurídicas. Outrossim, o aprofundamento nesse campo proporciona a criação de subcategorias de estudos, visto que ao descortinar as condutas outros aspectos acabam por tomar forma, como ocorre nos chamados safety crimes (crimes a salvo ou em segurança) (HYLLARD; TOMBS, 2013, p. 179).

Embora pertencente a uma subcategoria distinta, quando comparado aos abusos violentos de agentes do poder punitivo, os safety crimes trazem uma boa exemplificação de como ocorre o mascaramento dessas 
condutas, haja vista que usualmente os danos sociais advindos de suas atividades (ligadas ao universo laboral) são tipificadas como "acidentes" ou "desastres" (TOMBS, WHYTE, 2007, p. 2). Nesse caso, observe-se que os termos indicam uma ausência de intencionalidade, algo que busca rememorar os fundamentos de atuação penal, ao mesmo tempo em que realizam a imunização pela falta de previsibilidade dos autores crimes corporativos ou estatais, mesmo que em relação ao presente estudo se esteja a focar em atos violentos.

Apesar de uma caracterização particular, a menção acima apresenta a fórmula contumaz a ser seguida para as violações, sejam elas corporativas ou estatais. Apresenta-se assim um contexto caótico em que o sistema penal adiciona seletivamente violência ao caldo cultural brasileiro desigual, sempre resguardado por barreiras que impedem sua responsabilidade. No entanto, a abordagem criminológica oferta a possibilidade de dar voz as vítimas e aos sujeitos esquecidos pelo "desenvolvimento" proposto pela modernidade e que deixa corpos pelo caminho (SARMIENTO et al., 2014, p. 42).

Diante disso as vias criminológicas e de sustentabilidade intercalamse na oposição a este modelo de Estado e suas ações, que conduzem ao incremento das desigualdades sociais e à eliminação de seres humanos. Porém, ainda se justifica a inserção no âmbito da atuação penal direta (agências de controle e definições legais), ou seja, quais as recentes posturas nacionais denotam o reforço da via punitiva e o afastamento de um projeto socialmente sustentável, no que toca à violência enquanto instrumento padrão das forças de coerção penal.

\section{CRIMES DE ESTADO: A LEGITIMAÇÃO DA ATUAÇÃO POLICIAL VIOLENTA E OS INSTRUMENTOS JURÍDICOS DE “NORMALIZAÇÃO”}

Primeiramente, a adoção de um enfoque criminológico com base no dano social não é restritiva, ou seja, ela não significa a exclusão das análises legais ou mesmo da atuação do sistema penal na produção desses danos (HYLLARD; TOMBS, 2013, p. 191). Esse alerta pontual se 
justifica a fim de evitar o erro interpretativo de que ao desvincular-se das noções do crime se estaria ignorando os efeitos advindos da atuação penal na sociedade.

Um segundo fator de pré-compreensão situa-se na composição de área, pois os crimes estatais encontram-se alocados no que se compreende por crimes dos poderosos (crimes of the powerful), sendo estes focados na violação de direitos e vulnerabilizações causados por agentes pertencentes às corporações, mercados e Estados. Contudo, isso não pode induzir à confusão entre violação de direitos e danos sociais, já que o primeiro funcionaria ainda subordinado ao universo jurídico, bem como seria demasiadamente amplo (COHEN, 1996, p. 15).

Posto isso, os crimes perpetrados pelo Estado encaixam-se na noção de produção de danos sociais massivos, tendo o sistema penal como meio de execução, ao mesmo tempo em que se imunizam as condutas que não serão perseguidas pelo mesmo agente que as realiza, ou seja, o Estado.

Nesse sentido, a modificação para este modelo de Estado de Polícia, o qual encontra-se contido no interior de todo Estado de Direito (ROSA; AMARAL, 2017, p. 25), atualmente ganha em proporção quando comparado ao segundo, em razão de sua constante expansão. Segundo explica Wacquant a verificação do encolhimento social do Poder Público e da inaptidão para solucionar os problemas econômicos (ao menos no tocante a grande massa de trabalhadores e desempregados) vem acompanhado do reforço do braço punitivo do Estado no sentido de manter o controle da desigualdade crescente em quase que a totalidade dos países desenvolvidos (WACQUANT, 2007, p. 30).

Porém essa expansão punitiva não se restringe à dinâmica dos países com maior nível de desenvolvimento ou qualidade de vida, já que no âmbito brasileiro o reforço das vias penais é uma constante nos últimos tempos. Essa observação se dá também pela obviedade da falta de poder dos Estados em restringir os atuais poderes econômicos do mercado globalizado (MORAIS; WERMUTH, 2013, p. 163 - 164), o que leva à resposta punitiva como solução dos problemas sociais ao redor do mundo.

Nos contornos do consumo capitalista, basta projetar os sujeitos classificados como "maus consumidores" para perceber que a eles o 
sistema penal serve como a forma de remoção social aplicada. Por isso o Estado de Polícia precisa crescer, para assim dar conta da expulsão de dejetos humanos produzidos, visto que toda sociedade de consumo precisa de um bom serviço de lixo, no caso aqui o sistema penal (especialmente a prisão como depósito) (BAUMAN, 2008, p. 31).

Com isso, os marginalizados perdem progressivamente as condições materiais para o exercício dos direitos humanos de primeira geração e para exigir o cumprimento dos de segunda e terceira gerações. Eles se tornam "descartáveis", vivendo sem leis protetivas garantidas efetivamente e, condenados à marginalidade socioeconômica e a condições hobbesianas de existência - ante a ausência de um "soberano" —, não mais aparecendo como detentores de direitos públicos subjetivos; todavia, isso não significa que serão dispensados das obrigações estabelecidas pelo Estado: este os mantêm vinculados ao sistema jurídico por meio de suas normas penais. Aqui e agora, as instituições judiciais do Estado assumem funções eminentemente punitivo-repressivas, em detrimento da proteção dos direitos civis e políticos e da garantia da eficácia dos direitos sociais (MORAIS; WERMUTH, 2013, p. 166).

Assim, o Estado de Polícia ou Penal cresce sem perder de vista os cidadãos "inaptos" em sua rotina de exclusão social, já que o rigor da legislação penal se apresenta nesta relação de exceção, que somente inclui alguém por meio da exclusão (AGAMBEN, 2010, p. 25). Logicamente que ao se mensurar a totalidade desses posicionamentos os danos sociais produzidos se multiplicam em um caleidoscópio de variações que vão desde de prejuízos/lesões diretas até privações e traumas emocionais de árdua mensuração tanto dos autores de condutas desviantes quanto das pessoas a eles relacionadas (HYLLARD; TOMBS, 2013, p. 184 - 185).

Justifica-se a atuação expansiva com base no aumento da criminalidade e nos discursos causadores de alarma social (medo, risco, etc.), para com isso utilizar o apoio indignado e generalizado da população como sustentáculo. Igualmente esses argumentos validam uma suposta resposta às condutas de colarinho branco e outras espécies perpetradas em grande estilo, mas em realidade as pontuais e seletivas responsabilizações simbólicas (com todos os acordos e vantagens 
possíveis) obscurecem as proteções aos crimes dos poderosos e as imunidades criadas (ANDRADE, 2012, p. 170).

Há, portanto, a percepção de que a hipertrofia do Estado de Polícia é direcionada novamente aos mesmos públicos, sendo que as suas variantes de novas legislações contêm diversas zonas de escape às condutas que geram danos sociais massivos. 0 que, diante do caos social propagado, além de abalizado, torna o estado de exceção a regra geral, capaz de justificar toda e qualquer violação, desde que em prol do bem maior: a segurança da população (AGAMBEN, 2010, p. 26 - 27).

O contexto relatado fica mais verossímil ao passar do plano da criminalização primária, em teoria igualitária, para a perspectiva secundária transformando-se rapidamente na perseguição de inimigos sociais (indesejados), os quais usualmente são aqueles que realizam as obras mais toscas da seara penal (KHALED JÚNIOR, 2016, p. 48 - 49). Embora não se esteja a legitimar ações que atinjam outros seres humanos, a leitura ora proposta diz respeito a como se dá a atuação estatal nesses casos, ou seja, como é utilizada a violência.

Isso significa que a despeito das possibilidades dos crimes de Estado, atenta-se aqui aqueles praticados no uso regular da violência dita legítima (embora nem o sistema detenha hoje esse requisito) pelas agências de controle social.

Antes de adentrar nas peculiaridades recentes é salutar mencionar o aspecto histórico das forças policiais no país, sendo que sua atuação sempre foi impulsionada no sentido da violência autoritária, a qual era resguardada pela própria população (nas camadas mais baixas de renda, com a inserção de que os desviantes seriam "ainda piores" e merecedores de coerção). Essa visão construída na lógica de que o sujeito que viola a lei não merece direitos (não é considerado "cidadão de bem") se trata de uma variante seletiva do inimigo que precisa ser controlado pela polícia com o uso da violência (SOUZA, 2007, p. 77).

Mesmo com o transcurso do tempo as raízes históricas da atuação policial violenta são relegitimadas contemporaneamente por todas as camadas da população. Aponta-se assim que há um entendimento padronizado de que a solução para criminalidade passa por uma atuação violenta e manutenção da ordem, ainda que muitos dos apoiadores dessas 
ideias sejam igualmente os alvos preferenciais da atuação excessiva do poder coercitivo dos agentes policiais. Origina-se nessa dualidade o que French nomeia como paradoxo da opinião pública, o qual deslegitima o sistema penal "enquanto consolida os baixos índices de confiança da população na polícia” (FRENCH, 2017, p. 12).

Entretanto, para que essa atuação violenta possa ser realizada impõe-se a policização, haja vista que da mesma forma que ocorre a vitimização dos seres humanos mais vulneráveis, em geral é nas mesmas camadas sociais que se arrecadam as massas que compõem os órgãos de controle policial, e que também sofrem processos semelhantes. Afirmase a seletividade na definição dessas autoridades que devem conviver com a incongruência externa moralizante e interna com corrupções ou no mínimo de "flexibilizações legais" (ZAFFARONI, 1991, p. 138). Com tal padrão a violação de direitos humanos é normalizada, ocasionando o desvio de função sempre abalizado pela manutenção da ordem pública (GUIMARÃES; TORRES; FARIA, 2005, p. 264).

Segundo Zaffaroni a policização produz uma situação de anomia sobre o indivíduo. Essa alusão diz respeito ao fato da ruptura dos referenciais dos grupos que pertence, os quais passam a vê-lo como um estranho "e a tratá-lo com certa desconfiança; os grupos médios não o aceitam e, em geral, o desprezam; as cúpulas o ameaçam com sanções administrativas, se não se submeter a práticas corruptas", enquanto forçam um discurso moralizante, isso gera que o padrão de comportamento estipulado do herói ficcional é em realidade em certo grau de psicopata. Complementa ainda o autor supra dizendo que a anomia, juntamente à perda da identidade produz a deterioração do sujeito e, por conseguinte, o seu abalo intelectual e emocional, capaz de dificultar a atuação racional (ZAFFARONI, 1991, p. 139).

Cabe mencionar que as práticas violentas fazem parte da estratégia de segmentação social entre indivíduos a serem alvo da atuação e os policiais em treinamento, "para que o policial membro de classe popular negue o estigma potencial direcionado a esse tipo de segmento, produzindo representações e práticas repressivas que afirmem ser ele 'diferente' daqueles sobre os quais sua ação é voltada” (SOUZA, 2007, p. 78). 
A negação ao pertencimento de raça ou classe por meio da postura violenta traz à tona outros dois paradoxos da violência policial no Brasil. Nesse sentido o primeiro paradoxo explicita a questão racista na intervenção (negro-sobre-negro), enfatizando a contradição de um corpo policial formado em grande parte por homens e mulheres nãobrancos, mas que reforça todos os preconceitos contra a população negra. Ademais, o segundo paradoxo, do repúdio, configura-se com a resposta pública do governo negativa aos atos violentos da polícia, criando-se uma estigmatização dos agentes policiais, isso ironicamente não impede que estes realizem a repetição da violência estigmatizante contra a população (FRENCH, 2017, p. 13).

Logo, a violência como modo de agir, superando as barreiras legais, torna-se ordinária, bem como não se reduz em significância os atos publicizados ao imputar individualmente os desvios de conduta, mas sim constata-se a postura institucional do Estado de Polícia em suas instituições de controle. Ao mesmo tempo em que se justificam tais ações por meio do ideal de segurança, mantém-se a continuidade de sujeitos matáveis no Brasil, podendo-se rememorar o caso Amarildo, de forma singular, ou a totalidade recorrente das prisões para averiguações ou os autos de resistência, onde se observa a formalização de instrumentos de legitimação para o extermínio de parte da população considerada descartável (ROSA; AMARAL, 2017, p. 101).

Em direção análoga estão os dados apresentados pelo Human Rights Watch acerca do trabalho policial no Rio de Janeiro, que no caso convalidam a violência e a eliminação de seres humanos como conduta não somente aceitável dentro das corporações policiais, mas antes de tudo estimulada hierarquicamente, sob pena de "sanções" sobre o policial. Além disso outras condutas desviadas eram verticalmente direcionadas aos subordinados, o que leva a ocorrência de alteração nos locais de crimes, providências médicas como forma de ocultar execuções ou (supostos) equívocos de abordagem (encaminhamentos dessa ordem não fazem parte das competências dos agentes), adulteração de provas (remoção de peças de roupas das vítimas ou intimidação de testemunhas) ou até mesmo plantar evidências (armas ou simulação de troca de tiros) (HUMAN RIGHTS WATCH, 2016). 
A partir disso, ao mensurar os valores mais significativos, percebese que a segurança aparece no ápice juntamente às ideias de hierarquia e obediência, as quais em conjunto formatam os pressupostos de uma atuação violenta contra todo e qualquer cidadão, mesmo que as condutas sejam pouco significantes. Forma-se assim o raciocínio paradoxal de que a polícia para cumprir "ordens" (expressas ou implícitas) acabe descumprindo a lei, em outras palavras, "a fim de cumprir 'a ordem' que seria manter a segurança/ordem pública, a qualquer custo, sem importarse como isso seria alcançado (se for preciso eliminar parte da população isso é aceitável, segundo essa linha de pensamento)" (DIAS, 2017, p. 92).

Outra amostra das incongruências internas nas forças policiais pode ser corroborada pela leitura do Estatuto dos Servidores da Polícia Civil do estado do Rio Grande do Sul, pois neste consta que torturar ou violentar um preso é uma violação de ordem média, enquanto emitir um conceito desfavorável sobre um superior hierárquico é uma infração grave (ROSA; AMARAL, 2017, p. 102). Isso reflete a construção interna da legitimidade da violência enquanto ferramenta do Estado de Polícia, ou seja, a violência policial no país é uma questão endêmica e não pontual, como alguns discursos buscam afirmar a cada "desvio de conduta" de um agente policial.

O caso de Jhonata Dalber Alves expõe de forma evidente o problema da violência policial (letal), demonstrando que o silenciar sobre a questão produz morte e dor, mas que isso não fica restrito às vítimas diretas e indiretas das ações. Essa afirmativa tem por base a construção midiática de um responsável, de modo a suportar o peso da violência policial de forma solitária, como se isso fosse algo isolado, eximindo assim a corporação e seus companheiros de farda. Portanto, o que os agentes policiais não percebem é que a seletividade e discriminação se aplicam igualmente a eles, e no momento oportuno o "Judas" será sacrificado em nome de manter protegido o aparelho de violência desse Estado de Polícia deturpado (DIAS, 2017, p. 97).

Assim, a cegueira acerca da dimensão do problema da violência abusiva dos agentes do sistema penal torna-se ainda mais densa, quando patrocinada pelos meios de comunicação, pois esses últimos acabam por fomentar além de discursos de legitimação, igualmente demandas 
por segurança pública. Apenas de forma tangencial cabe referir que o crescimento nos investimentos em segurança e combate à criminalidade também refletem um Estado desigual, bem como o mau funcionamento da sociedade, já que "o dinheiro que é gasto em «segurança» - proteção da vida e da propriedade - não acrescenta nada ao bem-estar; apenas previne que as coisas" piorem (STIGLITZ, 2016, p. 75).

Conforme outras espécies de crimes dos poderosos que também contam com "danos colaterais" (BARAK, 2015, p. 105), a violência policial enquanto crime de Estado comporta-se dessa mesma forma, pois ao se retratar a ideia de uma "guerra" contra a criminalidade, as ações letais das autoridades servem como única resposta capaz de manter a ordem e acabar com os inimigos (já que em guerra não há cidadão e sim inimigo), e em um combate sempre existem as baixas. Significa que o discurso de embate constante não se trata se uma mera fala ou argumentação, e sim serve como outro elemento de legitimação, juntamente à ausência de alternativas, o que simplifica atos criminosos e abusivos a meros cumprimentos da ordem e de ordens, já que a brutalidade seria "mera decisão técnica orientada por uma plataforma abstrata e os sujeitos seus meros 'cumpridores de ordens', situação geradora de um 'sistema diabólico' que ninguém mais responde por si” (ROSA; AMARAL, 2017, p. 102).

Os dados dos últimos anos revelam o quadro mórbido da violência no país, pois o número de oficiais mortos cresce em velocidade semelhante ao de civis mortos nas atuações policiais (dinâmica da guerra e seus danos sociais massivos). Segundo o Anuário Brasileiro de Segurança Pública de 2017, o aumento no número de policiais mortos foi de 23,1\% (somando um total de 453 policiais mortos em 2016), sendo que esse número é superado pelo aumento ainda mais elevado no número de pessoas mortas em atuações policiais com cerca de 25,8\% (totalizando 4.222 pessoas) (LIMA et al., 2017, p. 7).

Tais informações se tornam ainda mais caóticas quando se apresenta o número de pessoas mortas nas atuações policiais desde o ano de 2009 até 2016, resultando em cerca de 21.892 pessoas mortas (LIMA et al., 2017, p. 7). Salutar dizer que a constatação do problema da violência policial como uma questão velada pelo Estado de Polícia contemporâneo que se agiganta 
perante o Estado de Direito é apenas uma parte da necessidade latente de modificação, ou seja, existe uma gama de ações forçosas para impedir as ações em curso, bem como o seu incremento latente.

Nesse norte a tentativa de "legalizar" a morte de criminosos por parte de policiais tem o apoio dos órgãos legislativos, algo que se corporifica com o projeto de lei no 352 (de 2017) do senador José Medeiros em curso no Senado, que prevê a aplicação automática da legítima defesa caso o sujeito esteja portando ostensivamente uma arma de fogo de uso restrito (inclusão de um parágrafo no atual artigo 25 do Código Penal) (BRASIL, 2017). Por óbvio que o autor do projeto apresenta a periculosidade desses armamentos como justificativa, mas jamais tocaria na possibilidade de corrupção dos órgãos de controle social, apesar das já declaradas manobras de plantar ou enxertar provas ou armas por parte das autoridades (HUMAN RIGHTS WATCH, 2016).

Não bastasse o uso da legislação como forma de legitimar ações violentas, as quais são simplificadas na perspectiva da expansão penal (aumento de crimes e penas), somam-se ainda os desvios punitivos das autoridades policiais. Em recente demonstração disso está o caso do Delegado de polícia que se utilizando de falsas provas (testemunhas em especial) imputou mortes de crianças e um suposto ritual de satanismo, proferindo para tanto diversas declarações inflamatórias da população contra os criminosos (que se fossem nomeados de infiéis ou hereges não estariam tão distantes da inquisição) ${ }^{2}$ (THE INTERCEPT BRASIL, 2018).

Por mais que o caso não tenha uma agressão física (embora o cerceamento da liberdade possa se enquadrar nesta situação), a violência policial institucional opera igualmente de forma injusta, desigual e seletiva, violando direitos e produzindo danos sociais massivos contra parcela da população. Ademais, localizar o aumento do Estado de Polícia do ponto de vista de atos lesivos e violentos diretos (e letais) é bastante simples, basta para tanto observar a situação da intervenção militar no Rio de Janeiro, na qual os integrantes de comando clamam por mudanças legais que os autorizariam a alvejar pessoas nas ruas por estarem armadas (FOLHA DE SÃO PAULO, 2018), e ao mesmo tempo conta-se com a morte de pessoas que apresentam oposições ou críticas a violência policial (e militar) (UOL, 2018). 
Apontam-se essas situações concretas a fim de apresentar a multiplicidade das faces da violência policial no Brasil, para que com isso se observem tais crimes de Estado enquanto situação caótica estrutural e não meramente pontual. Em síntese, revela-se aqui uma situação insustentável do ponto de vista social, de modo que não há qualquer expectativa de uma sociedade mais justa e igualitária quando os instrumentos do Estado de Direito são transmutados na legalização de escusas de atos violentos na construção de um Estado de Polícia ilegítimo e produtor de massivos danos sociais.

Diante disso, o enfrentamento da violência policial não deve ser simplificado a um combate aos agentes ou à corrupção, mas sim compreendido na complexidade dos interesses políticos e econômicos que movem o Estado contemporâneo na direção da coerção e do aumento das desigualdades, para que somente assim se repensem as estruturas dos órgãos de coerção social para além de meros reprodutores de violência e produtores de danos sociais, tanto para policiais quanto para a população brasileira.

\section{CONCLUSÃO}

A busca por uma sociedade sustentável apresenta-se aqui como um projeto para a humanidade, ao passo que serve também como função crítica às posturas violentas realizadas. Destarte, a duplicidade ofertada pelas construções da sustentabilidade social não impede de citá-la em sua pluralidade de competências, embora aqui opte-se por apresentar tanto a visão de renovação quanto a de incisão/oposição.

Indica-se com isso a relevância de contestar conceitualmente os rumos desiguais produzidos na trajetória humana, mas ao mesmo tempo questionar o papel do sistema penal para a carência da sociedade e os danos sociais produzidos por ele. Com fulcro nesta articulação de pressão que impõe a autorreflexão da própria criminologia (mudança epistemológica) e seu papel como instrumento de ocultação de danos sociais massivos é que se intercalam aqui as perspectivas criminológico- 
críticas e de sustentabilidade social, a fim de analisar a situação do uso da violência e do crescimento do Estado de Polícia contemporâneo.

Dito isso, compreende-se que o aumento da via punitiva estatal guarda vínculos com aspectos econômicos e políticos, mas tais fatos acabam desviados para ingerências na seara da segurança e combate à criminalidade, legitimando assim não apenas o incremento do sistema penal, como igualmente a legitimação da postura violenta dos agentes do controle social. Apresentam-se um conjunto de ações articuladas que legitimam e legalizam a violência policial no país, a fim de que essa seja a principal ferramenta de controle a ser utilizada pelo Estado de Polícia, que cresce em detrimento do Estado de Direito.

Portanto, a conclusão desta pesquisa se dá na direção da insustentabilidade social do atual Estado de Polícia que se constrói no Brasil, o qual adota a violência policial como umas das suas formas de atuação em detrimento da garantia de direitos e de justiça social, sempre amparada pelas facilidades dos crimes dos poderosos. Diante disso, enquanto não houver um repensar das instituições que direcionam o sistema penal, além da direção atual tomada pelo Estado, não há qualquer possibilidade de a noção de sustentabilidade alcançar a significância necessária para reduzir desigualdades e melhorar as condições de vida de uma população agredida e violada diuturnamente.

\section{NOTAS}

1 Cabe registrar que ainda hoje existem autores atentos a diferenciação entre poder e violência, que embora aqui associados não são uma relação necessária, conforme se vislumbra nas palavras de Barreto (2012, p. 40 -41): "expressa a violência, assim, um instrumento usado muitas vezes no exercício do poder mas não se confunde com ele, pois em função dela pode-se distinguir o poder nu, desprovido de qualquer justificativa, do poder legitimado pela autoridade. Representa, entretanto, um instrumento que se constitui em fator determinante nas lutas pelo poder, razão pela qual muitas vezes associamos violência e poder".

2 O Delegado em questão era conhecido por ser um religioso fervoroso, inclusive tendo nomeado a operação de "Revelação". 


\section{REFERÊNCIAS}

AGAMBEN, Giorgio. Homo sacer: o poder soberano e a vida nua. 2 ed. Belo Horizonte: Editora UFMG, 2010.

ANDRADE, Vera Regina Pereira de. Pelas mãos da criminologia: o controle penal para além da (des)ilusão. Rio de Janeiro: Revan, 2012.

ARENDT, Hannah. Sobre la violencia. Madrid: Alianza Editorial, 2006.

ARENDT, Hannah. The human condition. 2 ed. Chicago: University of Chicago Press, 1998.

BARAK, Greg. The crimes of the powerful and the globalization of crime. Revista Brasileira de Direito. v. 11, n. 2, p. 104 - 114, jul-dez. 2015.

BARATTA, Alessandro. Criminologia crítica e crítica do direito penal: introdução à sociologia do direito penal. 3 ed. Rio de Janeiro: Revan, 2002.

BARRETO, Vicente de Paulo. As máscaras do poder. São Leopoldo: Editora Unisinos, 2012.

BAUMAN, Zygmunt, Vida para consumo: a transformação das pessoas em mercadoria. Rio de Janeiro, Jorge Zahar, 2008.

BOFF, Leonardo. A terra na palma da mão: uma nova visão do planeta e da humanidade. Petrópolis: Vozes, 2016.

BOFF, Leonardo. Sustentabilidade: o que é - o que não é. 4 ed. Petrópolis: Vozes, 2015.

BOSSELMANN, Klaus. 0 princípio da sustentabilidade: transformando direito e governança. São Paulo: Revista dos Tribunais, 2015.

BRAGATO, Fernando Frizzo. Para além do discurso eurocêntrico dos direitos humanos: contribuições da descolonialidade. Revista novos estudos jurídicos. Itajaí, v. 19, n. 1, jan/abr., 2014, p. 201-230. 
BRASIL. Constituição Federal. 1988. Disponível em: <http://www.planalto. gov.br/ccivil_03/constituicao/constituicaocompilado.htm>. Acesso em $11 \mathrm{de}$ março de 2018.

BRASIL. Projeto de Lei no 352 de 2017. Disponível em: <https://www25. senado.leg.br/web/atividade/materias/-/materia/130958?o=d $>$. Acesso em 18 de março de 2018.

BUDÓ, Marília De Nardin. Mídias e discursos do poder: a legitimação discursiva do processo de encarceramento da juventude pobre no Brasil. Tese (Doutorado em Direito) - Curso de Pós-Graduação em Direito, Universidade Federal do Paraná, Curitiba, 2013.

CANOTILHO, José Joaquim Gomes. O princípio da sustentabilidade como princípio estruturante do direito constitucional. Revista de Estudos Politécnicos. Vol. VIII, no 13, 007-018, 2010.

CARLEN, Pat. Criminologias alternativas. In: CARLEN, Pat; FRANÇA, Leandro Ayres (Org.). Criminologias alternativas. Porto Alegre: Canal Ciências Criminais, 2017. p. $19-34$.

CARVALHO, Salo. Criminologia crítica: dimensões, significados e perspectivas atuais. Revista brasileira de ciências criminais. n. 104. São Paulo: Revista dos Tribunais, 2013. p. 279 - 303.

CARVALHO, Salo; DUARTE, Evandro Piza. Criminologia do preconceito: racismo e homofobia nas Ciências Criminais. São Paulo: Saraiva, 2017.

COELHO, Elza Berger Salema; SILVA, Anne Caroline Luz Grüdtner da; LINDNER, Sheila Rubia. Violência: definições e tipologias. 2014.

COHEN, Stanley. Crime and politics: spot the difference. The British Journal of Sociology. v. 47, n. 1, p. $1-21,1996$.

DAHLBERG, Linda L.; KRUG, Etienne G. Violência: um problema global de saúde pública. Ciência \& Saúde Coletiva, v. 11, p. 1163-1178, 2006.

DIAS, Felipe da Veiga. A violência (mortal) do Estado contra criança e adolescentes: um estudo a partir do retrato midiático do caso Jhonata Dalber 
Mattos Alves. Revista brasileira de ciências criminais. Ano 25, n. 130, abril, 2017.

ELKINGTON, John, Cannibals With Forks: The Triple Bottom Line of 21st Century Business. Stony Creek, Conn.: New Society Publishers, 1998.

FOLHA DE SÃO PAULO. Comandante do Exército defende mudança em regras de enfrentamento no Rio: alteração permitiria que um militar alvejasse um homem na rua por portar arma. Disponível em: https://www1.folha.uol.com. $\mathrm{br} /$ cotidiano/2018/02/comandante-do-exercito-defende-mudanca-em-regrasde-enfrentamento-no-rio.shtml. Acesso em 18 de março de 2018.

FOUCAULT, Michel. Vigiar e punir: nascimento da prisão. 27 ed. Petrópolis: Vozes, 2003.

FREITAS, Felipe. Novas perguntas para criminologia brasileira: poder, racismo e direito no centro da roda. Cadernos do CEAS. Salvador, n. 238, 2016. p. 488 - 499.

FRENCH, Jan Hoffman. Repensando a Violência Policial no Brasil: Desmascarando o Segredo Público da Raça. Revista Tomo. n. 31 jul./dez., 2017. p. 9 - 40.

GUIMARÃES, Juliany Gonçalves; TORRES, Ana Raquel Rosas; FARIA, Margareth. R. G. V. de. Democracia e violência policial: o caso da polícia militar. Psicologia em estudo. v. 10, n. 2, 2005. p. $263-271$.

HARVEY, David. 17 contradições e o fim do capitalismo. São Paulo: Boitempo, 2016.

HILLYARD, Paddy; TOMBS, Steve. ¿Más allá de la criminología? Revista Crítica Penal y Poder. n. 4, p. 175 - 196, marzo. 2013.

HUMAN RIGHTS WATCH. Good cops are afraid: the toll of unchecked police violence in Rio de Janeiro. 2016.

KHALED JÚNIOR, Salah H. Discurso de ódio e sistema penal. Belo Horizonte: Casa do Direito/Letramento, 2016.

LARRAURI, Elena. La herencia de la criminología crítica. 2 ed. Madrid: Siglo XXI Editores España, 1992. 
LIMA, Renato Sérgio de; et al.. Anuário Brasileiro de Segurança Pública 2017. São Paulo: Fórum Brasileiro de Segurança Pública, 2017.

MCKENZIE, Stephen. Social sustainability: towards some definitions. Hawke Research Institute. Working Paper Series, n. 27. Magill: South Australia, 2004. p. $1-29$.

MORAIS, Jose Luis Bolzan de; WERMUTH, Maiquel Ângelo Dezordi. A Crise do Welfare State e a Hipertrofia do Estado Penal. Seqüência. n. 66, p. 161-186, julho, Florianópolis: 2013.

MORIN, Edgar. A via para o futuro da humanidade. 2 ed. Rio de Janeiro: Bertrand Brasil, 2015.

PAVARINI, Massimo. Control y dominación: teorías criminológicas burguesas y proyecto hegemónico. Buenos Aires: Siglo XXI Editores Argentina, 2002.

ROSA, Alexandre Morais da; AMARAL, Augusto Jobim do. Cultura da punição: a ostentação do horror. 3 ed. Florianópolis: Empório do Direito, 2017.

SARMIENTO, Camilo Ernesto Bernal; CABEZAS, Sebastián; FORERO, Alejandro; RIVERA, Iñaki; VIDAL, Iván. Más allá de la criminología. Un debate epistemológico sobre el daño social, los crímenes internacionales y los delitos de los mercados. In: RIVERA, Iñaki (Coord.). Delitos de los Estados, de los Mercados y daño social: debates en criminología crítica y sociología jurídico-penal. Barcelona: Anthropos, 2014. p. 35 - 80.

SOUZA, Marcos Santana de. Representações sociais, polícia e violência: um estudo sobre a violência policial. Scientia Plena. v. 3, n. 5, 2007. p. 75 - 82.

STIGLITZ, Joseph E.. O preço da desigualdade. Lisboa: Bertrand Editora, 2016.

THE INTERCEPT BRASIL. Como um delegado usou testemunhas falsas para ligar a morte de crianças a um ritual satânico. Disponível em: <https:// theintercept.com/2018/03/02/novo-hamburgo-satanico-inquerito/>. Acesso em: 18 de março de 2018.

TOMBS, Steve; WHYTE, Dave. Safety crimes. London/New York: Routledge, 2007. 
UOL. Notícias internacional. Imprensa internacional destaca morte de Marielle: 'ataque direcionado' e 'crítica da violência policial'. Disponível em: <https://noticias.uol.com.br/internacional/ultimas-noticias/2018/03/15/ imprensa-internacional-destaca-morte-de-marielle-ataque-direcionado-ecritica-da-violencia-policial.htm>. Acesso em: 18 de março de 2018.

WACQUANT, Loïc. Punir os pobres: a nova gestão da miséria nos Estados Unidos. 3 ed. Rio de Janeiro: Revan, 2007.

WORLD HEALTH ORGANIZATION. Global consultation on violence and health. Violence: a public health priority. Geneva: WHO; 1996.

YOUNG, Jock. A sociedade excludente: exclusão social, criminalidade e diferença na modernidade recente. Rio de Janeiro: Revan, 2002.

ZAFFARONI, Eugenio Raúl. Em busca das penas perdidas: a perda de legitimidade do sistema penal. Rio de Janeiro: Revan, 1991.

ZAFFARONI, Eugenio Raúl. "Introducción" a criminología, civilización y nuevo orden mundial de Wayne Morrison. Revista Crítica Penal y Poder. no 2, p. 1 - 17, marzo. 2012.

Enviado em: 20-3-2018

Recebido em: 19-12-2019 


\section{Felipe da Veiga Dias}

Pós-doutor em Ciências Criminais pela PUC/RS; doutor em Direito pela Universidade de Santa Cruz do Sul (UNISC) com período de Doutorado Sanduíche na Universidad de Sevilla (Espanha); professor do Programa de PósGraduação em Direito da Faculdade Meridional (IMED) - Mestrado; professor do curso de Direito da Faculdade Meridional (IMED) - Passo Fundo - RS. Brasil; coordenador do Grupo de Pesquisa "Criminologia, Violência e Sustentabilidade Social"; e advogado.

\section{Augusto Jobim do Amaral}

Doutor em Altos Estudos Contemporâneos (Ciência Política, História das Ideias e Estudos Internacionais Comparativos) pela Universidade de Coimbra; doutor; mestre; especialista em Ciências Criminais pela Pontifícia Universidade Católica do Rio Grande do Sul (PUCRS); e professor do Programa de Pós-Graduação em Ciências Criminais (Mestrado e Doutorado) da PUCRS.

IMED - Passo Fundo - RS

R. Gen. Prestes Guimarães, 304 - Vila Rodrigues, Passo Fundo - RS, 99070-220 
